\title{
Epidemiology of elderly patients hospitalized in intensive care unit for severs medical illnesses
}

\author{
Rhita Bennis Nechba ${ }^{1,2}$, Moncif El M'barki Kadiri ${ }^{3}$, Amine Ali Zeggwagh ${ }^{4}$, \\ Abdelhalim Mesfioui ${ }^{2}$ \\ ${ }^{1}$ Department of Critical Care, El Idrissi Regional Hospital, Kenitra, Morocco \\ ${ }^{2}$ Laboratory of Genetic, Neuroendocrinology and Biothechnology, Ibn Tofaîl University, Kenitra \\ ${ }^{3}$ Department of Nephrology, Dialysis and Transplantation, Military Hospital, Rabat, Morocco \\ ${ }^{4}$ Department of Medical Intensive Care, Ibn Sina University Hospital, Rabat, Morocco and Laboratory of Biostatistique, of Clinical \\ Recherche and Epidemiology, Mohammed V University of Medicine and Pharmacy, Rabat, Morocco
}

\section{Email address:}

bennirhita@yahoo.fr(R. B. Nechba),monkadiri@yahoo.fr(M. El M'barki Kadiri), aazeggwagh@invivo.edu(A. A. Zeggwagh), a.mesfioui@yahoo.fr(A. Mesfioui)

\section{To cite this article:}

Rhita Bennis Nechba, Moncif El M’barki Kadiri, Amine Ali Zeggwagh, Abdelhalim Mesfioui. Epidemiology of Elderly Patients Hospitalized in Intensive Care Unit for Severs Medical Illnesses. Science Journal of Public Health. Vol. 1, No. 5, 2013, pp. $215-221$. doi: 10.11648/j.sjph.20130105.15

\begin{abstract}
Objectives: This study was made to identify the epidemiological data of elderly patients (over 65 years of age) vs. younger patients $(<65$ years) requiring admission to the intensive care unit for severs medical illnesses. Design and patients: We conducted an analysis of a prospective observational study of 106 adults admitted to the intensive care unit for severs medical illnesses, from January 2010 to January 2012. Patients admitted to the intensive care unit for surgical illnesses were excluded. Setting: A 6-bed polyvalent intensive care unit in a regional hospital. Results: The study group included $31(29 \%)$ elderly patients $(\geq 65$ years of age) and $75(71 \%)$ young patients $(<65$ years of age $)(n=106)$. Elderly patients tended to have a higher simplified acute physiology score version II in admission ( 36 vs $21, \mathrm{p}<0,001)$. There were several epidemiological differences between the two groups: Chronic diseases were more frequent in elderly patients than in younger one (diabetes $(55 \%$ vs $20 \%$; $<<0,001)$, high blood pressure $(45 \%$ vs $13 \% ; p<0,001)$ and heart diseases $(48 \%$ vs $19 \% ; p=0,002)$. Elderly patients were significantly more hospitalized for delirium comparing to younger one ( $87 \%$ vs $64 \%$; $\mathrm{p}=0,017$ ), but dyspnea was less percepted by elderly patients $29 \%$ vs $55 \%$ for younger patients, $p=0,016$. Acute respiratory distress syndrome, acute heart failure, acute kidney injury, were all more frequent in elderly patients respectively ( $p=0,006$, $\mathrm{p}=0,014, \mathrm{p}=0,005)$. The incidence of death was $37 \%$ for all patients and it was similar between the two groups $(\mathrm{p}=0,251)$. Conclusion: The identification of epidemiology of older patients hospitalized in intensive care unit for severs medical illnesses will help to develop qualified practice. Further studies are needed to better characterize those elderly individuals who may be at the highest risk of complications.
\end{abstract}

Keywords: Intensive Care Unit, Elderly, Epidemiology

\section{Introduction}

Older patients tend to have complex clinical presentations, and their care can be resource-intensive [1]. Due to demographic change and progress in medicine, the percentage of geriatric patients treated in intensive care is continuously increasing [2]. In addition to acute diseases, many of those patients may also have chronic illnesses, multimorbidity, and cognitive limitations [2]. Mortality among old patients is high, but functionality and comorbidity have a great effect on patient outcome [3]. Structural and functional organ changes have an additional impact on the treatment of geriatric patients in intensive care [3]. There are no studies directly investigating epidemiology of hospitalized elderly patients for severe medical illnesses in intensive care unit (ICU) in our hospital. The objective of our study was to evaluate the epidemiologic profile of those patients and to compare our results with international findings. 


\section{Materials and Methods}

We conducted a 2-year prospective observational study to evaluate elderly patients admitted in ICU of Idrissi's hospital, Kenitra, Morocco, for severs medical illnesses. Two groups were compared according to age $(<65$ years and $\geq 65$ years). Collected data included sociodemographic and medical baseline data, the Simplified Acute Physiology Score version II (SAPS II) was calculated based on the worst variables recorded during the first 24 hours of ICU admission [4], reason of hospitalization, antecedents, diagnostics, length of stay, discharge disposition and death. We used universally accepted definitions in order to validate comparisons across multiple studies. The participating center is a regional hospital having access to a polyvalent intensive care unit with 6 beds. During the two years of the study, every newly elderly patient admitted to ICU for medical illness was registered and was followed up until intensive care discharge or death in ICU. We were asked to complete the data entry. Upon arrival, all data were screened in detail by a dedicated intensive care specialist. Any queries planned resolution within 48 h. Categorical variables were expressed as percentages and continuous variables as the median and interquartile range (25th-75th IQR). Categorical variables were compared between older patients and younger patients using the chi-square or Fisher's exact test, and continuous variables using the nonparametric Mann-Whitney test as appropriate. P value $\leq$ 0.05 was considered statistically significant. All analysis was performed by the SPSS statistical software package 13.0.

\section{Results}

106 patients were included; 75(71\%) young and 31(29\%) old. Information was collected for each patient. Elderly patients tended to have a higher SAPS II in admission than younger patients ( 36 vs $21, \mathrm{p}<0,001)$. Concerning reasons of intensive care admissions, delirium was more frequent in elderly comparing to younger patients (87\% vs. $64 \%$, $\mathrm{p}=0,017)$. Twenty nine percent of elderly patients percept dyspnea vs $55 \%$ of younger one, $\mathrm{p}=0,016$. Characteristics of patients during ICU staying and reasons of ICU admission are summarized in table 1 .

Table 1. Characteristics of patients during ICU staying and reason of ICU admission.

\begin{tabular}{|c|c|c|c|c|}
\hline Parameters & $\begin{array}{c}\text { All patient } \\
n=106\end{array}$ & $\begin{array}{c}\text { Young } \\
n=75\end{array}$ & $\begin{array}{c}\text { Old } \\
n=31\end{array}$ & $\mathbf{p}$ \\
\hline Patient number, n (\%) & $106(100)$ & $75(71)$ & $31(29)$ & \\
\hline Age (years), median (IQR) & $53[28-69]$ & $45[24-56]$ & $72[70-80]$ & $<0,001$ \\
\hline SAPS II. Score, median (IQR) & $29[19-41]$ & $21[16-37]$ & $36[33-50]$ & $<0,001$ \\
\hline Female, n (\%) & $51(48)$ & $39(52)$ & $12(39)$ & \multirow{2}{*}{0,213} \\
\hline Male, n (\%) & $55(52)$ & $36(48)$ & $19(61)$ & \\
\hline Mechanical ventilation & $30(28)$ & $22(29)$ & $8(26)$ & 0,714 \\
\hline \multicolumn{5}{|l|}{ Reason of ICU admission } \\
\hline Delirium, n (\%) & $75(71)$ & $48(64)$ & $27(87)$ & 0,017 \\
\hline Shock, n (\%) & 20(19) & $15(20)$ & $5(16)$ & 0,643 \\
\hline Dyspnea, n (\%) & $50(47)$ & $41(55)$ & $9(29)$ & 0,016 \\
\hline One vital distress, $\mathrm{n}(\%)$ & $78(74)$ & $54(72)$ & $24(77)$ & \\
\hline Two vital distresses, n (\%) & $18(17)$ & 14(19) & $4(13)$ & \\
\hline Tree vital distresses, $\mathrm{n}(\%)$ & $10(9)$ & $7(9)$ & $3(10)$ & 0,771 \\
\hline
\end{tabular}

$\mathrm{n}$ : number

IQR: interquartile range

SAPSII Score: Simplified Acute Physiology Score version II

ICU: intensive care unit

There were several epidemiological differences between the two groups: the incidence of diabetes was higher in elderly $55 \%$ vs $20 \%$ in younger patients $(\mathrm{p}<0,001)$, high blood pressure was significantly more registered in elderly
$45 \%$ vs $13 \%$ for younger patients $(\mathrm{p}<0,001)$, such us antecedents of heart diseases $48 \%$ vs $19 \%(p=0,002)$ (table 2). 
Table 2. Antecedents of patients.

\begin{tabular}{|c|c|c|c|c|}
\hline Parameters & $\begin{array}{c}\text { All patients } \\
\mathrm{n}=106\end{array}$ & $\begin{array}{c}\text { Young } \\
\mathrm{n}=75\end{array}$ & $\begin{array}{c}\text { Old } \\
\mathrm{n}=31\end{array}$ & $\mathbf{P}$ \\
\hline Smoking; n (\%) & $16(15)$ & $13(17)$ & $3(10)$ & 0,247 \\
\hline High Blood Pressure ; n (\%) & $24(23)$ & $10(13)$ & $14(45)$ & $<0,001$ \\
\hline Diabetes; $\mathbf{n}(\%)$ & $32(30)$ & $15(20)$ & $17(55)$ & $<0,001$ \\
\hline Heart diseases; n (\%) & $29(27)$ & $14(19)$ & $15(48)$ & 0,002 \\
\hline Tuberculosis; $\mathrm{n}(\%)$ & $9(8,5)$ & $8(11)$ & $1(3)$ & 0,278 \\
\hline COPD; n (\%) & $11(10)$ & $9(12)$ & $2(6)$ & 0,503 \\
\hline Asthma n (\%) & $4(4)$ & $4(5)$ & $0(0)$ & 0,319 \\
\hline Chronic kidney injury; n (\%) & $9(8,5)$ & $6(8)$ & $3(10)$ & 0,719 \\
\hline Malignancy; n (\%) & $4(4)$ & $3(4)$ & $1(3)$ & 1 \\
\hline Epilepsy; n (\%) & $5(5)$ & $3(4)$ & $2(6)$ & 0,628 \\
\hline Surgery; n (\%) & $6(6)$ & 2(3) & $4(13)$ & 0,059 \\
\hline
\end{tabular}

COPD: chronic obstructive pulmonary disease

Acute respiratory distress syndrome (ARDS), acute heart in elderly patients (table 3 ). failure, acute kidney injury (AKI), were all more frequent

Table 3. Diagnostics.

\begin{tabular}{|c|c|c|c|c|}
\hline Parameters & $\begin{array}{c}\text { All patients } \\
n=106\end{array}$ & $\begin{array}{c}\text { Young } \\
\mathrm{n}=75\end{array}$ & $\begin{array}{c}\text { Old } \\
\mathrm{n}=\mathbf{3 1}\end{array}$ & $\mathbf{P}$ \\
\hline Cerebral stroke & $19(18)$ & $11(15)$ & $8(26)$ & 0,174 \\
\hline Shock & $36(34)$ & $24(32)$ & $12(39)$ & 0,507 \\
\hline Sever sepsis & $79(74,5)$ & $53(71)$ & $26(84)$ & 0,156 \\
\hline Acute heart diseases & $50(47)$ & 29(39) & $21(68)$ & $\mathbf{0 , 0 0 6}$ \\
\hline Epilepsy & $22(21)$ & $17(23)$ & $5(16)$ & 0,450 \\
\hline Hyperosmolar hyperglycemic state & $16(15)$ & $8(11)$ & $8(26)$ & 0,071 \\
\hline Acute respiratory distress syndrome & $59(56)$ & $36(48)$ & $23(74)$ & $\mathbf{0 , 0 1 4}$ \\
\hline Asthma & $4(4)$ & $4(5)$ & $0(0)$ & 0,319 \\
\hline Chronic obstructive pulmonary disease & $12(11)$ & $10(13)$ & 2(6) & 0,502 \\
\hline Poisoning & $10(9)$ & $9(12)$ & 1(3) & 0,275 \\
\hline Hepatic dysfunction & $31(29)$ & $18(24)$ & $13(42)$ & 0,065 \\
\hline Acute Kidney injury & $46(43)$ & $26(35)$ & $20(64,5)$ & 0,005 \\
\hline Thrombocytopenia; n (\%) & $30(28)$ & $20(27)$ & $10(32)$ & 0,561 \\
\hline Anemia; n (\%) & $44(41,5)$ & $30(40)$ & $14(45)$ & 0,624 \\
\hline
\end{tabular}

The incidence of death was $37 \%$ for all patients. In our population, the incidence of mortality, and the median of

ICU stay were similar between the two groups (table 4).

Table 4. Length of stay and mortality.

\begin{tabular}{lcccc}
\hline Parameters & $\begin{array}{c}\text { All patients } \\
\mathbf{n = 1 0 6}\end{array}$ & $\begin{array}{c}\text { Young } \\
\mathbf{n = 7 5}\end{array}$ & $\begin{array}{c}\text { Old } \\
\mathbf{n = 3 1}\end{array}$ & P \\
\hline Length of stay in hospital before ICU admission (days); median (IQR) & $1[1-2]$ & $1[1-2]$ & $1[1-2]$ & 0,235 \\
ICU stay (days); median (IQR) & $4[1-7]$ & $4[2-7]$ & $4[1-7]$ & 0,552 \\
ICU mortality; n (\%) & $39(37)$ & $25(33)$ & $14(45)$ & 0,251 \\
\hline
\end{tabular}

$\mathrm{n}$ : number

IQR: interquartile range

ICU: intensive care unit 


\section{Discussion}

The aging of the population has increased the demand for healthcare resources. With advancing age, the proportion of various preexisting comorbidities and the primary reasons for ICU admission change. In our study, $87 \%$ of elderly were hospitalized in ICU for delirium. Acute confusional state is common, serious, costly, and often fatal particularly in the elderly $[5,6]$. It is responsible for up to $56 \%$ of hospital admissions in the elderly [7]. Delirium can be precipitated by almost any medical condition or pharmacological treatment and may be the only symptom of illness $[6,7]$. Epileptic activities occur in a significant proportion of delirium, and possibly have a role in the prognosis. In our study it occurred in $16 \%$ of elderly patients. Acute symptomatic seizures are very frequent most often due to metabolic abnormalities; infections or medications [8]. Electroencephalography should be carried out in all older patients with delirium [7]. The incidence of stroke was $26 \%$ in our elderly patients. Stroke incidence typically increases with age and, due to the ageing of the population, stroke incidence rates are expected to rise [9].

Dyspnea is an alarming symptom responsible for millions of patient visits each year [10]. In our study, older patients had significantly lower perception of dyspnea compared to younger ones. The blunted perception of dyspnea might be reasonably attributed to an inappropriately low level of fear and inadequate earlier medical treatment for both patients and physicians, resulting in subsequent intensive care [10]. It is related to hospitalization, high medical costs, and all-cause mortality in community-dwelling elderly people [10].

The incidence of diabetes was significantly higher in elderly $(55 \%)$ than in younger patients $(20 \%)(\mathrm{p}<0,001)$. In developed countries, $12-25 \%$ of the aged population (>65 years old) have diabetes [11]. It is universally acknowledged that diabetes mellitus is a common cause of morbidity in the elderly population and it's a significant contributor to mortality and reduced life expectancy in elderly subjects $[12,13]$.

Blood pressure was measured in the sitting position and also with the patient standing (when possible) to exclude orthostatic hypotension, a frequent problem in elderly patients [14]. Pseudo-hypertension, a source of inadequate measurements in elderly patients was recognized [14]. High blood pressure was significantly more frequent in elderly patients than in younger ones. Hypertension is very common and inadequately controlled among the elderly [15]. Antecedents of heart diseases were significantly more frequent in elderly. Elderly patients are particularly susceptible to chronic heart failure and pulmonary diseases, which are classical causes of respiratory failure needing ICU admission [16, 17].

Acute heart failure was significantly more frequent in elderly. Acute coronary syndrome is more frequent in the elderly than in the general population and is associated with very high morbidity and mortality [18, 19]. Prevention of cardiovascular diseases was probably underused in our elderly patients, even if it is efficient, and that could explain also complications and hospitalization in ICU [20].

ARDS was significantly more frequent in elderly. The aged patients are susceptible to respiratory failure, especially acute lung injury (ALI) or ARDS [21]. The mortality rate for ARDS ranges from $40-70 \%$ despite of a correct resuscitation [21]. Careful hemodynamic monitoring and resuscitation combined with other strategies to ameliorate non pulmonary organ dysfunction achieved good outcomes in high-risk patients and could contribute in the future to further improved outcomes of elderly patients with ARDS [22].

The incidence of anemia in our geriatric patients was high $(45 \%)$. With some variations in different patient cohorts, prevalence of anemia can reach 40\% [23]. Anemia is not an age-related disease on its own, but is a symptom with multifactorial genesis and high risk potential [23]. It directly influences mortality, morbidity, and the rate of hospitalization, particularly in older patients suffering from chronic heart failure or chronic kidney disease [23].

The sepsis and septic shock represent the most frequent causes of morbidity and mortality in the ICU [24]. In our study, severe sepsis was the leading etiologic factor of hospitalization in ICU. Eighty four percent of older patients presented severe sepsis. Elderly patients are at particular risk for bacteremia and sepsis [24]. Atypical presentation may complicate the diagnosis [25]. Sepsis is a disease of elderly people. Indeed, $60 \%$ of all sepsis events and $80 \%$ of septic deaths occur in individuals over 65 years-old [26]. The incidence increases exponentially with age and older age is an independent risk factor for mortality among adults hospitalized with sepsis [26]. Elderly patients are particularly exposed to the risk of nosocomial infections [27]. Advanced age and multiple comorbidities compromise their immunity and hence they may be more prone to succumbing to severe infection and have poorer outcome [28]. Only prevention may reduce the impact of infections on this frail population [29-31]. It is believed that continued research will result in a decrease in infection morbidity and mortality in elderly.

The incidence of AKI (during hospital admission) ranges from 3 to $25 \%$ depending on criteria applied [32]. The variety of definitions used in clinical studies may be partially responsible for the large variations in the reported incidence and the associated mortality (19-83\%) of AKI [33-35]. AKI is a common complication of critical illness [36]. The increased incidence of AKI is most likely due to a trend of admitting older, more severely and more chronically ill patients to hospitals [37-39]. In our study, AKI patients were significantly older. In the aging population, there is heightened susceptibility to drug toxicity, partially owing to altered drug pharmacokinetics and pharmacodynamics. Furthermore, elderly people consume twice as many medications overall, including 
nephrotoxic agents, than younger patients [39, 40]. Sepsis, diabetes, hypovolemia, nephrotoxic drugs and cardiovascular diseases are among the common causes of AKI in elderly patients [41, 42].

There was no difference concerning hepatic dysfunction between old and young patients. Hepatic dysfunction is a common finding in critically ill patients on the ICU and directly influences survival [43]. Hypoxic hepatitis may be induced by hemodynamic instability or arterial hypoxemia in critically ill patients [44]. In other way patients with cirrhosis are prone to infection which is a frequent precipitant of hepatic encephalopathy [45]. Finally, patients in the ICU have multiorgan dysfunction as well as altered pharmacokinetic parameters. Hence they are susceptible to adverse drug reactions like hepatic dysfunction [46].

The incidence of thrombocytopenia was $28 \%$ for all patients. Thrombocytopenia, which is one of the most commonly observed laboratory abnormalities in the ICU population, has an incidence ranging from $13.0 \%$ to $44.1 \%$, depending on the study population, the timing and frequency of platelet monitoring, and the definition of thrombocytopenia [47].

In our study, the incidence of death was $37 \%$ for all patients. Our work found out also that age was not a risk factor of mortality. Death is common place in the ICU [48] It is estimated that one in five Americans and $50 \%$ of hospitalized patients die using intensive care [48]. Elsewhere and in India, depending on the case mix 10-36\% of patients admitted to ICU die [48]. Many investigations have shown that age alone is not associated with poor prognosis in the ICU [49-51]. Other factors, including patient selection criteria, primary disease, co-morbidity, severity of illness and complications, significantly influence outcome $[49,52]$.

\section{Conclusion}

The identification of epidemiology of elderly patients hospitalized in medical intensive care will help develop qualified practice. Basic geriatric knowledge should be part of the curricula of intensive care. Further studies are necessary to support the hypothesis that quality gains may be achieved by creating a geriatric unit at the hospital.

\section{Limits of the Study}

Our results are limited by the number of patients. It was often very difficult to clinically determine the cause of dyspnea, especially in the elderly. Our study protocol did not require an invasive hemodynamic monitoring; we could not assess exactly the volume-status of patients on ICUadmission. The diagnosis of hypovolemia was based mainly on basic hemodynamic data and clinical impressions. We did not detail the treatment, second adverse neither long-term outcome. Future studies are needed to evaluate more points about elderly in our region.

\section{Abbreviations}

ICU: intensive care unit; SAPS II: simplified acute physiology score; AKI: acute kidney injury; ARDS: acute respiratory distress syndrome. COPD: chronic obstructive pulmonary disease.

\section{References}

[1] Teresita M. Hogan, MD, Eve D. Losman, MD, Christopher R. Carpenter, MD, Karen Sauvigne, MA, Cheryl Irmiter, $\mathrm{PhD}$,Linda Emanuel, MD, PhD, and Rosanne M. Leipzig, MD. Development of Geriatric Competencies for Emergency Medicine Residents Using an Expert Consensus Process. Acad Emerg Med. 2010; 17(3): 316-324.

[2] Simon A. Geriatric patients in intensive care medicine. Ethical aspects. Med Klin Intensivmed Notfmed. 2011;106 (1):24-8.

[3] Singler K, Christ M, Sieber C, Gosch M, Heppner HJ. Geriatric patients in emergency and intensive care medicine. Internist (Berl). 2011;52(8):934-8.

[4] Le Gall JR, Lemeshow S, Saulnier F: A new Simplified Acute Physiology score (SAPS II) based on a European/North American multicenter study. JAMA 1993 ; 270:2957-63.

[5] Neerland BE, Watne LO, Wyller TB. Delirium in elderly patients. Tidsskr Nor Laegeforen. 2013;133(15):1596-600.

[6] Inouye SK, Westendorp RG, Saczynski JS. Delirium in elderly people. Lancet. 2013 Aug 27. pii: S01406736(13)60688-1. doi: 10.1016/S0140-6736(13)60688-1. [Epub ahead of print]

[7] Naeije G, Bachir I, Gaspard N, Legros B, Pepersack T. Epileptic activities are common in older people with delirium.Geriatr Gerontol Int. 2013 Aug 4. doi: 10.1111/ggi.12128. [Epub ahead of print]

[8] Greffard S, Barrou Z, Godard M, Verny M. Epilepsy in the elderly. Rev Prat. $2011 ; 61(10): 1343-8$.

[9] Béjot Y, Rouaud O, Jacquin A, Osseby GV, Durier J, Manckoundia P, Pfitzenmeyer P, Moreau T, Giroud M. Stroke in the very old: incidence, risk factors, clinical features, outcomes and access to resources--a 22-year population-based study. Cerebrovasc Dis. 2010 ;29(2):11121.

[10] Ebihara S, Niu K, Ebihara T, Kuriyama S, Hozawa A, Ohmori-Matsuda K, Nakaya N, Nagatomi R, Arai H, Kohzuki M, Tsuji I. Impact of blunted perception of dyspnea on medical care use and expenditure, and mortality in elderly people. Front Physiol. 2012; 3:238.

[11] Ardigo S, Perrenoud L, Philippe J. Diabetes in elderly: a tailored management. Rev Med Suisse. 2013; 9(389):1192-6, 1198-9.

[12] Sinclair AJ, Robert IE, Croxson SC. Mortality in older people with diabetes mellitus. Diabet Med. 1997;14(8):63947.

[13] Corriere M, Rooparinesingh N, Kalyani RR. Epidemiology of Diabetes and Diabetes Complications in the Elderly: An 
Emerging Public Health Burden.Curr Diab Rep. 2013 Sep 11. [Epub ahead of print]

[14] Schoenenberger AW, Erne P, Stuck AE. Hypertension in the elderly. Ther Umsch. 2012; 69(5):299-304.

[15] Hanon O. Hypertension in the elderly: particularities and precautions. Presse Med. 2009; 38(4):614-20.

[16] Frederique Schortgen, Arnaud Follin, Lucilla Piccari, Ferran Roche-Campo, Guillaume Carteaux, Elodie Taillandier-Heriche, Sebastien Krypciak, Arnaud W Thille, Elena Paillaud, and Laurent Brochard2,4,5 Results of noninvasive ventilation in very old patients. Ann Intensive Care. 2012; 2: 5

[17] Nagase T. Respiratory failure Nihon Rinsho. 2013; 71(6):1031-4.

[18] Falconnet C, Carballo S, Roffi M, Keller PF, Perrenoud JJ. Acute coronary syndrome: guidelines and geriatrics specificity. Rev Med Suisse. 2009; 5(204):1137-8, 1140-2, 1144-7.

[19] Shanmugasundaram M, Alpert JS. Acute coronary syndrome in the elderly. Clin Cardiol. 2009; 32(11):608-13.

[20] Belmin J, Chauvelier S, Friocourt P. Prevention of coronary heart disease and heart failure in the elderly. Rev Prat. 2009; 59(10):1389-95.

[21] Nagase T. Respiratory failure. Nihon Rinsho. 2013; 71(6):1031-4.

[22] Eachempati SR, Hydo LJ, Shou J, Barie PS. Outcomes of acute respiratory distress syndrome (ARDS) in elderly patients.J Trauma. 2007; 63(2):344-50.

[23] Röhrig G, Doehner W, Schaefer RM, Schulz RJ. Anemia and iron deficiency in the elderly. Prevalence, diagnostics and new therapeutic options. Z Gerontol Geriatr. 2012 ; 45(3):191-6).

[24] Astrid L Wester, 囚1 Oona Dunlop,2 Kjetil K Melby,3,4 Ulf $\mathrm{R}$ Dahle, 1 and Torgeir Bruun Wyller3,5 Age-related differences in symptoms, diagnosis and prognosis of bacteremia. BMC Infect Dis. 2013; 13: 346.

[25] Heppner HJ, Cornel S, Peter W, Philipp B, Katrin S. Infections in the elderly. Crit Care Clin. 2013; (3):757-74.

[26] Pinheiro da Silva F, Zampieri FG, Barbeiro DF, Barbeiro HV, Goulart AC, Torggler Filho F, Velasco IT, da Cruz Neto LM, de Souza HP, Machado MC. Septic shock in older people: a prospective cohort study. Immun Ageing. 2013; 10(1):21. doi: $10.1186 / 1742-4933-10-21$

[27] Bourdel-Marchasson I, Kraus F, Pinganaud G, TexierMaugein J, Rainfray M, Emeriau JP. Annual incidence and risk factors for nosocomial bacterial infections in an acute care geriatric unit. Rev Med Interne. 2001;22(11):1056-63.

[28] Nasa P, Juneja D, Singh O, Dang R, Arora V. Severe sepsis and its impact on outcome in elderly and very elderly patients admitted in intensive care unit. J Intensive Care Med. 2012; 27(3):179-83.

[29] Chami K, Gavazzi G, de Wazières B, Lejeune B, Carrat F, Piette F, Hajjar J, Rothan-Tondeur M. Guidelines for infection control in nursing homes: a Delphi consensus webbased survey. J Hosp Infect. 2011; 79(1):75-89.
[30] Chami K, Gavazzi G, Carrat F, de Wazières B, Lejeune B, Piette F, Rothan-Tondeur M. Burden of infections among 44,869 elderly in nursing homes: a cross-sectional cluster nationwide survey. J Hosp Infect. 2011; 79(3):254-9.

[31] Laurent M, Bories PN, Le Thuaut A, Liuu E, Ledudal K, Bastuji-Garin S, Paillaud E. Impact of comorbidities on hospital-acquired infections in a geriatric rehabilitation unit: prospective study of 252 patients. J Am Med Dir Assoc. 2012;13(8):760

[32] Medve L, Csaba A, Paloczi B, Kocsi S, Gartner B, Marjanek $\mathrm{Z}$ et al. Epidemiology of acute kidney injury in Hungarian intensive care units: a multicenter, prospective, observational study. BMC Nephrology 2011; 12:43.

[33] Pisoni R, Wille KM, Tolwani AJ: The epidemiology of severe acute kidney injury: from BEST to PICARD, in acute kidney injury: new concepts. Nephron Clin Pract 2008; 109:188-91.

[34] Silvester W, Bellomo R, Cole L: Epidemiology, management, and outcome of severe acute renal failure of critical illness in Australia. Crit Care Med 2001 ; 29:1910-5.

[35] Vincent JL: Incidence of acute renal failure in the intensive care unit. Contrib Nephrol 2001, 132:1-6.

[36] Odutayo A, Adhikari NK, Barton J, Burns KE, Friedrich JO, Klein D et al. Epidemiology of acute kidney injury in Canadian critical care units: a prospective cohort study. Can J Anaesth. 2012 Jul 28. [Epub ahead of print]

[37] De Mendonca A, Vincent JL, Suter PM, Moreno R, Dearden $\mathrm{NM}$, Antonelli $\mathrm{M}$ et al. Acute renal failure in the ICU: risk factors and outcome evaluated by the SOFA score. Intensive Care Med 2000; 26:915-21.

[38] Kolhe NV, Stevens PE, Crowe AV, Lipkin GW, Harrison DA Case mix, outcome and activity for patients with severe acute kidney injury during the first 24 hours after admission to an adult, general critical care unit: application of predictive models from a secondary analysis of the ICNARC Case Mix Programme Database. Critical Care 2008; 12:S2.

[39] Coca SG: Acute kidney injury in elderly persons. Am J Kidney Dis 2010; 56:122-31.

[40] Himmelfarb J: Acute kidney injury in the elderly: problems and prospects. Semin Nephrol 2009; 29:658-64.

[41] Wen J, Cheng Q, Zhao J, Ma Q, Song T, Liu S et al. Hospital-acquired acute kidney injury in Chinese very elderly persons. J Nephrol. 2012 May 28:0. doi: 10.5301/jn.5000182. [Epub ahead of print]

[42] Zhou Q, Zhao C, Xie D, Xu D, Bin J,Chen P et al. Acute and acute-on-chronic kidney injury of patients with decompensated heart failure: impact on outcomes. BMC Nephrology 2012; 13:51.

[43] Koch A, Horn A, Dückers H, Yagmur E, Sanson E, Bruensing J, Buendgens L, Voigt S, Trautwein C, Tacke F. Increased liver stiffness denotes hepatic dysfunction and mortality risk in critically ill non-cirrhotic patients at a medical ICU. Crit Care. 2011;15(6):R266. doi: 10.1186/cc10543. Epub 2011 Nov 14.

[44] Raurich JM, Llompart-Pou JA, Ferreruela M, Colomar A, Molina M, Royo C, Ayestarán I, Ibáñez J. Hypoxic hepatitis 
in critically ill patients: incidence, etiology and risk factors for mortality. J Anesth. 2011; 25(1):50-6.

[45] Shawcross DL, Sharifi Y, Canavan JB, Yeoman AD, Abeles RD, Taylor NJ, Auzinger G, Bernal W, Wendon JA. Infection and systemic inflammation, not ammonia, are associated with Grade 3/4 hepatic encephalopathy, but not mortality in cirrhosis.J Hepatol. 2011; 54(4):640-9.

[46] Joshua L, Devi P, Guido S. Adverse drug reactions in medical intensive care unit of a tertiary care hospital. Pharmacoepidemiol Drug Saf. 2009;18(7):639-45.

[47] Lim SY, Jeon EJ, Kim HJ, Jeon K, Um SW, Koh WJ, Chung MP, Kim H, Kwon OJ, Suh GY. The incidence, causes, and prognostic significance of new-onset thrombocytopenia in intensive care units: a prospective cohort study in a Korean hospital. J Korean Med Sci. 2012; 27(11):1418-23.

[48] RK Mani, P Amin, R Chawla, JV Divatia, F Kapadia, P Khilnani, SN Myatra, S Prayag, R Rajagopalan, SK Todi, R Uttam. Guidelines for end-of-life and palliative care in
Indian intensive care units' ISCCM consensus Ethical Position Statement.Indien journal of critical care medicine.2012; 3 (16):166-81.

[49] Vosylius S, Sipylaite J, Ivaskevicius J. Determinants of outcome in elderly patients admitted to the intensive care unit. Age Ageing 2005;34:157-162.

[50] Sacanella E, Pe'rez-Castejo'n JM, Nicola's JM, et al. Mortality in healthy elderly patients after ICU admission. Intensive Care Med 2009;35:550-555.

[51] Torres $\mathrm{OH}$. Short- and long-term outcomes of older patients in intermediate care units. Intensive Care Med 2006;32:1052-1059.

[52] Walther SM, Jonasson U. Outcome of the elderly critically ill after intensive care in an era of cost containment. Acta Anaesthiol Scand 2004; 48:417-422. 